\title{
COVID-19 Antibody Testing of Patients Admitted to the ICU by a Novel, Point-of-Care Assay, and the Relationship to Survival
}

\section{Stacey Casswell}

AgPlus Diagnostics

\section{Ann-Katrin Eriksson}

Diagnostics Development

\section{Lena Moberg}

Uppsala University Hospital Department of Clinical chemistry and Pharmacology: Akademiska

Sjukhuset Klinisk kemi och farmakologi

\section{Miklos Lipcsey}

Uppsala University Department of Surgical Sciences

\section{Michael Hultström}

Uppsala University Hospital Department for Anaesthesiology and Intensive Care: Akademiska Sjukhuset Anestesi- och intensivvard ANIVA

\section{Robert Frithiof}

Uppsala University Hospital Department for Anaesthesiology and Intensive Care: Akademiska Sjukhuset Anestesi- och intensivvard ANIVA

Fiona Marshall

AgPlus Diagnostics

Per Venge ( $\square$ per.venge@medsci.uu.se)

Uppsala University: Uppsala Universitet https://orcid.org/0000-0001-5863-790X

\section{Research}

Keywords: COVID-19, IgG antibodies, Point-of-care test

Posted Date: March 10th, 2021

DOI: https://doi.org/10.21203/rs.3.rs-289303/v1

License: (1) (i) This work is licensed under a Creative Commons Attribution 4.0 International License. Read Full License 


\section{Abstract}

Diagnosing persons infected by COVID-19 is key to the control of the pandemic. It has, however, become increasingly important to identify those who have had the infection by measurement of circulating antibodies against Sars-COV-2 of the IgM and IgG type. In this report we show the development of a rapid and sensitive point-of-care assay for the measurement of IgG antibodies against the two spike proteins, S1 and S2, of the Sars-COV-2 virus.

Method

The AgPlus electrochemical technology was applied and the S1 and S2 proteins were biotinylated and immobilized onto streptavidin coated magnetic particles as the capture component of the assay. The IgG antibodies bound to the particles were detected by anti-human IgG and the signal expressed as $\mathrm{nC}$ (nano Coulomb). Assay time was $<10 \mathrm{~min}$.

Results

Plasma $(n=211)$ from 117 SARS-Cov-2 PCR positive patients and from 78 persons with samples taken before the COVID-19 pandemic were analysed. The sensitivity and specificity of the assay were $91.9 \%$ and $100 \%$, respectively. The assay was highly correlated to a predicate and FDA-approved IgG antibody ELISA $(r=0.81)$. The IgG response was significantly lower in patients who died during their ICU stay.

Conclusions

A poor IgG response after a COVID-19 infection is a serious risk factor as to death. A sensitive, rapid and accurate IgG antibody POC assay should be useful in the daily management and evaluation of COVID-19 infected patients.

\section{Background}

The COVID-19 pandemic is a major burden to the society. Diagnosing persons infected by COVID-19 is key to the control of the pandemic. It has, however, become increasingly important to identify those who have had the infection by measurement of circulating antibodies against Sars-COV-2 of the IgM and IgG type(1-4). IgM antibodies are present within days after acquiring the infection and subside within the next few weeks and replaced by IgG antibodies. The duration of IgG antibodies is uncertain, but their presence has been observed several months after the infection(5). Circulating IgG antibodies against the Sars-COV-2 are important for the immunity against the infection and is the aim of the vaccination programme.

Several assay formats have been developed for the identification of IgG antibodies against the spike proteins S1 and S2 of The Sars-COV-2 virus, however with very varying performances (6-10). Some of these assays are lab based and some based on lateral flow POC assays. The attraction of POC assays for this diagnostic purpose is the easy and rapid access to the knowledge of the antibody response, be it 
in the care of seriously ill patients at the ICU or for the estimate of the response after a vaccination or after a COVID-19 infection. In this report we show the development of a novel point-of-care assay of IgG antibodies against the two spike proteins. The validity of the POC assay was tested in a population of patients with serious COVID-19 infection admitted to the intensive care unit. The clinical utility of the IgG antibody assay was suggested by the close relation of the lgG response to the outcome of the patients with regards to mortality.

\section{Methods}

\section{Methods}

COVID-19 infected patients $(n=117)$ were admitted to the ICU due to respiratory failure on average 10 (range 2-34 days) days after a positive COVID-19 PCR test. Eighty-nine patients were men (age median 60 years, range $25-86$ years) and 28 women (age median 69 years, range $24-86$ years).

The present investigation is a sub-study of a prospective observational study carried out at the ICU at Uppsala University hospital, a tertiary care hospital in Sweden at the time only treating COVID-19 patients. The study was approved by the National Ethical Review Agency (EPM; No. 2020 - 01623). Informed consent was obtained from the patient, or next of kin if the patient was unable to give consent. The Declaration of Helsinki and its subsequent revisions were followed. The protocol of the study was registered a priori (Clinical Trials ID: NCT04316884). STROBE guidelines were followed for reporting.

De-identified plasma collected pre-pandemic between 2016-2018 from apparently healthy persons $(n=$ 76) were used as $\lg G$ antibody negative samples.

The AgPlus point-of-care technology was applied. The antigens used in the assay were the S1 and S2 COVID-19 subunits provided by The Native Antigen Company (Kidlington, UK). These proteins were biotinylated and immobilized onto streptavidin coated magnetic particles as the capture component of the assay. Diluted blood sample was added to a tube containing the dried streptavidin magnetic particles and allowed to incubate for three minutes. During the same incubation, dried $80 \mathrm{~nm}$ silver nanoparticle pre-coated with Mouse Anti Human IgG were rehydrated. Following a magnetic hold the sample supernatant was removed and replaced with the re-hydrate silver nanoparticles. The mouse Anti Human IgG binds to the Sars-COV-2 specific antibodies already bound to magnetic particles. Following another short incubation (3 minutes) and a magnetic hold, unbound silver particles were removed and the sample washed with a buffer solution. A further magnetic hold was performed and the wash buffer supernatant removed and replaced with an electrolyte containing read buffer. This sample was then added to an AgPlus electrode and the amount of silver present determined via anodic stripping voltammetry. The result was presented as nano Coulomb $(\mathrm{nC})$. The total assay time was $<10$ minutes.

Statistics 
Non-parametric statistics was applied. Comparison between groups was calculated by Mann-Whitney Utest and correlations by Spearman rank. The statistics programme MedCalc $®$ Statistical Software version 19.6 was used (MedCalc Software Ltd, Ostend, Belgium; https://www.medcalc.org; 2020). The determination of cut-off i.e., the limit between positive or negative IgG response was performed by Fleet Bioprocessing (Hartley Wintney,UK). A receiver operating characteristic curve was constructed. A receiver operating characteristic curve, or ROC curve, is a graphical plot that illustrates the diagnostic ability of a binary classifier system as its discrimination threshold is varied. The ROC curve is constructed by plotting the true positive rate against the corresponding false positive rate as the assay cut-off is varied.

The ROC curve data was used to determine the optimum assay cut-point. The ROC data was analysed in the following manner. Based upon the methodology of $\mathrm{Liu}(11)$, the $\mathrm{CZ}$ value was calculated as the product of the true positive rate and true negative rate for a given threshold value. In addition, the Youden function $(J)$ was calculated by subtracting the false positive rate from the true positive rate for a given value of threshold. The optimum cut-off can then be set to maximise the $\mathrm{CZ}$ or $\mathrm{J}$ value, giving the optimum balance between assay sensitivity and specificity. Both methods yielded the same optimum cutpoint for the assay.

Having determined the optimum cut-off, sample data were classified accordingly and the assay characteristics calculated as follows using a value of 0.95 for 1 -a (ie. $95 \%$ confidence interval, $\mathrm{Cl}$ ).

\section{Results}

The intra and inter-assay variations of the AgPlus IgG antibody assay were estimated by triplicates at three different levels. The intra-assay variation for the negative control (range 1937-4577 nC) was median 5.3\% CV (range 1.9-18.0\%), for the low positive control (range 7524-9999 nC) median CV 4.5\% (range 4.1$8.3 \%$ ) and for the high control (range 22519-27703 nC) median CV 5.5\% (range 5.4-7.4\%). The inter-assay variations were CV $4.5 \%, 1.6 \%$ and $1.1 \%$, respectively, at the three different levels.

Plasma ( $\mathrm{n}=211)$ was obtained from 117 patients with positive PCR tests for COVID-19 and used as positives whereas pre-pandemic plasma from the years 2016-2018 $(n=78)$ were used as negatives. The sensitivity of the test was $91.9 \%$ (95\% Cl $88.1 \%$ to $95.6 \%$ ) and the specificity $100 \%$ (95\% Cl $100 \%$ to $100 \%$ ) with a positive predictive value of $100 \%$ ( $95 \% \mathrm{Cl} 100 \%$ to $100 \%$ ) and a negative predictive value of $81.7 \%$ (95\% Cl $73.9 \%$ to $89.6 \%$ ). The cut-off between negative and positive IgG antibodies was set to $6100 \mathrm{nC}$ based on ROC-plots.

The AgPlus IgG antibody test was compared to an ELISA-based assay produced by ALPCO Inc and approved by FDA. As shown in figure 1 the two assays showed a highly significant correlation, $r=0.81$, $p<0.0001$. However, relative to the cut-offs of the two assays a proportion of samples $(22 \%)$ deemed positive by the AgPlus assay was below the cut-off of the ALPCO assay. Twenty of the samples were also tested by a lateral flow POC assay provided by Fortress Diagnostics (Co. Antrim, $\mathrm{N}$ Ireland). The concordance between this assay and the AgPlus assay was $75 \%$. 
As shown in figure 2, IgG antibodies against COVID-19 antigens were present in blood in $82 \%$ of the patients at admission to the ICU. The proportion of patients with positive response of IgG antibodies rose further during the stay at the ICU and was at day 3,96\%. A significantly higher proportion of the patients $(p=0.0038)$ who did not present with positive IgG antibody response died early after admission (figure 3 ). Eight of the patients died already within three days after admission to the ICU. In one patient who died after 2 weeks at the ICU, IgG antibodies did not show up at any time in her blood.

\section{Discussion}

The point-of-care technology described in this report proved to be both reliable and rapid in the detection of circulating IgG antibodies against Sars-COV-2 in patients with severe organ dysfunction as a consequence of COVID-19. In comparison to one ELISA based assay and a lateral-flow POC assay the AgPlus assay showed a superior performance. Importantly the specificity of the AgPlus assay was $100 \%$ which means that no false positives were obtained. The sensitivity was lower, which was expected, since not all subjects proven to have been infected by COVID-19 produce antibodies. This inability of the immune system to respond to the viral challenge may be detrimental to the individual as demonstrated recently(12). The current results concur the observation that individuals in intensive care due to COVID-19 with a poor IgG-response are at greater risk of dying compared to those who mount a high and positive response. Those few surviving patients who presented with low IgG antibody response at admission had all raised responses at day three. Only one patient remained with IgG titres below the cut-off during the follow-up for 14 days after which she died. Such observations emphasize the importance of the production of IgG antibodies to protect against the detrimental effects of the virus infection.

Monitoring of IgG antibodies against COVID-19 should be an important aid and complement in the fight against the pandemic and even more so in the monitoring of the efficacy of vaccination programmes $(1 ; 3-5 ; 8)$. From very preliminary data differences in the vaccines currently distributed and administered in the population can be seen in their varying efficacy in their protection for individuals against the virus infection. These differences may be related to age and individual immune capacities and monitoring the IgG response should be of great importance in order to achieve the best possible immunity in the population(8). For these purposes we need access to reliable high through put laboratory assays for mass screening $(4 ; 13)$, but also similarly reliable POC assays that can be used in settings not suitable for mass screening or when rapid answers to the immunization is warranted(7).

\section{Conclusions}

The assay presented in this report seems to fulfil the requirement of sufficient sensitivity and specificity in the detection of an IgG response after a Sars-COV-2 infection and should be a better choice for these purposes than most qualitative lateral flow assays in doctor's office settings.

\section{Declarations}




\section{Ethical Approval and Consent to participate}

The study was approved by the National Ethical Review Agency (EPM; No. 2020-01623). Informed consent was obtained from the patient, or next of kin if the patient was unable to give consent. The Declaration of Helsinki and its subsequent revisions were followed. The protocol of the study was registered a priori (Clinical Trials ID: NCT04316884).

\section{Consent for publication}

$\mathrm{Na}$

\section{Availability of supporting data}

$\mathrm{Na}$

\section{Competing interests}

None

\section{Funding}

The study was funded by the SciLifeLab/KAW national COVID-19 research program project grant to $\mathrm{MH}$ (KAW 2020.0182), and a Swedish Research Council grant to RF (2014-02569 and 2014-07606).

\section{Authors' contributions}

SC and FM developed the assay and initiated the study

AKE and LM validated the assay and collected patient samples

$\mathrm{ML}, \mathrm{MH}$ and $\mathrm{RF}$ were responsible for patient diagnosis and clinical data

PV initiated the study, put the data together and was the main author

All authors read, commented on the manuscript and eventually approved the paper

\section{Acknowledgements}

The authors thank the study nurses Elin Söderberg and Joanna Wessbergh and the biobank research assistants Philip Karlsson and Erik Danielsson for their expert help with compiling study data and organising sample analysis. We would also like to thank ALPCO Inc in Boston USA for analysing the samples with their ELISA system.

\section{References}


1. Kopel J, Goyal H, Perisetti A. Antibody tests for COVID-19. Proc (Bayl Univ Med Cent) 2020 Oct 13;34(1):63-72.

2. Ghaffari A, Meurant R, Ardakani A. COVID-19 Point-of-Care Diagnostics That Satisfy Global Target Product Profiles. Diagnostics (Basel) 2021 Jan 12;11(1).

3. Bermingham WH, Wilding T, Beck S, Huissoon A. SARS-CoV-2 serology: Test, test, test, but interpret with caution! Clin Med (Lond). 2020 Jul;20(4):365-8.

4. Krammer F, Simon V. Serology assays to manage COVID-19. Science 2020 Jun 5;368(6495):1060-1.

5. Zhao J, Yuan Q, Wang H, Liu W, Liao X, Su Y, et al. Antibody Responses to SARS-CoV-2 in Patients With Novel Coronavirus Disease 2019. Clin Infect Dis 2020 Nov 19;71(16):2027-34.

6. Van EJ, Houben E, Depypere M, Brackenier A, Desmet S, Andre E, et al. Diagnostic performance of seven rapid IgG/IgM antibody tests and the Euroimmun IgA/IgG ELISA in COVID-19 patients. Clin Microbiol Infect. 2020 Aug;26(8):1082-7.

7. Choe JY, Kim JW, Kwon HH, Hong HL, Jung CY, Jeon CH, et al. Diagnostic performance of immunochromatography assay for rapid detection of IgM and IgG in coronavirus disease 2019. J Med Virol. 2020 Nov;92(11):2567-72.

8. Whitman JD, Hiatt J, Mowery CT, Shy BR, Yu R, Yamamoto TN, et al. Test performance evaluation of SARS-CoV-2 serological assays. medRxiv 2020 May 17.

9. Robosa RS, Sandaradura I, Dwyer DE, O'Sullivan MVN. Clinical evaluation of SARS-CoV-2 point-ofcare antibody tests. Pathology 2020 Dec;52(7):783-9.

10. Furuya AKM, Wagner C, Connors J, Bodnar J, Miller T, Ryman NL, et al. Performance evaluation of antibody-based point-of-care devices intended for the identification of immune responses to SARSCoV-2. Diagn Microbiol Infect Dis 2020 Dec 24;99(4):115298.

11. Liu X. Classification accuracy and cut point selection. Stat Med. 2012;31(23):2676-86.

12. Asif S, Frithiof R, Lipcsey M, Kristensen B, Alving K, Hultstrom M. Weak anti-SARS-CoV-2 antibody response is associated with mortality in a Swedish cohort of COVID-19 patients in critical care. Crit Care 2020 Nov 6;24(1):639.

13. Houlihan CF, Beale R. The complexities of SARS-CoV-2 serology. Lancet Infect Dis. 2020 Dec;20(12):1350-1.

\section{Figures}




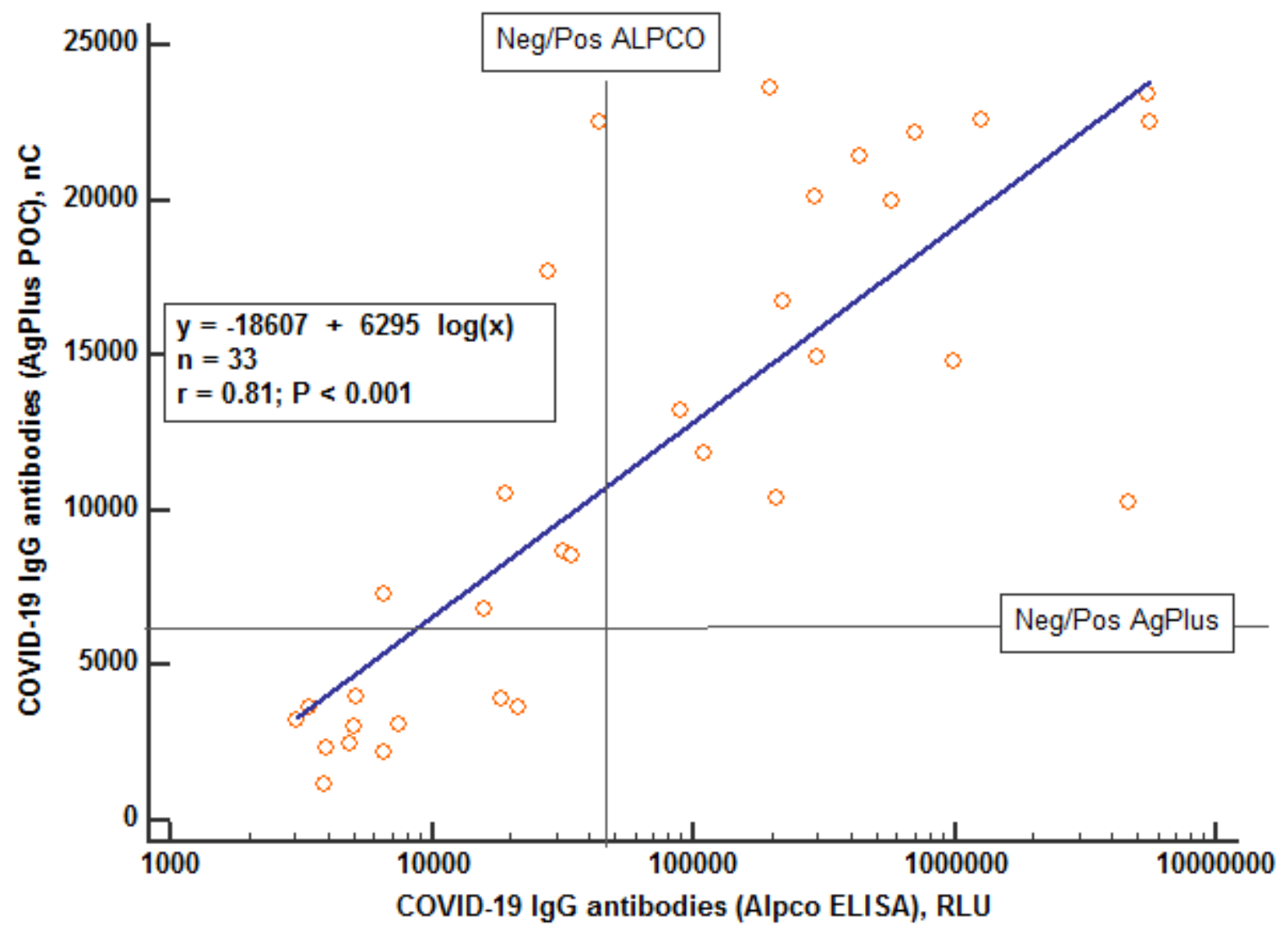

\section{Figure 1}

IgG antibody response as measured by the AgPlus assay in comparison to the Alpco ELISA for IgG antibodies against Sars-COV-2 virus. The results of a Spearman rank correlation are shown on the figure. The cut-offs, positive/negative IgG response, for the two assays are shown by horizontal and vertical lines, respectively. 


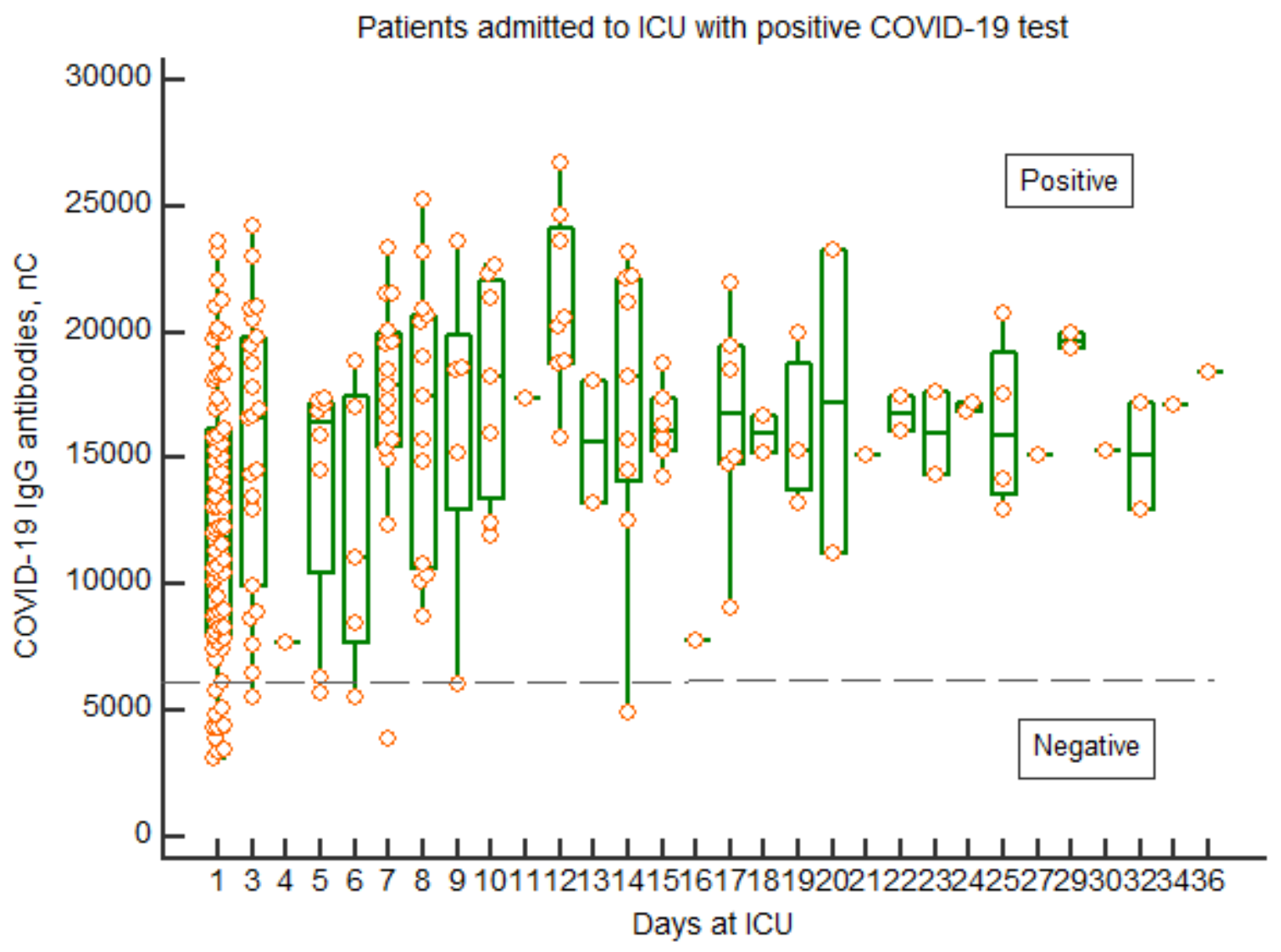

\section{Figure 2}

The figure shows the IgG antibody response over time in COVID-19 PCR positive patients admitted to the ICU. The boxes indicate medians and IQ range. The horizontal line indicates the cut-off between positive and negative IgG antibody responses. The response is expressed as $\mathrm{nC}$ (nano Coulomb). 


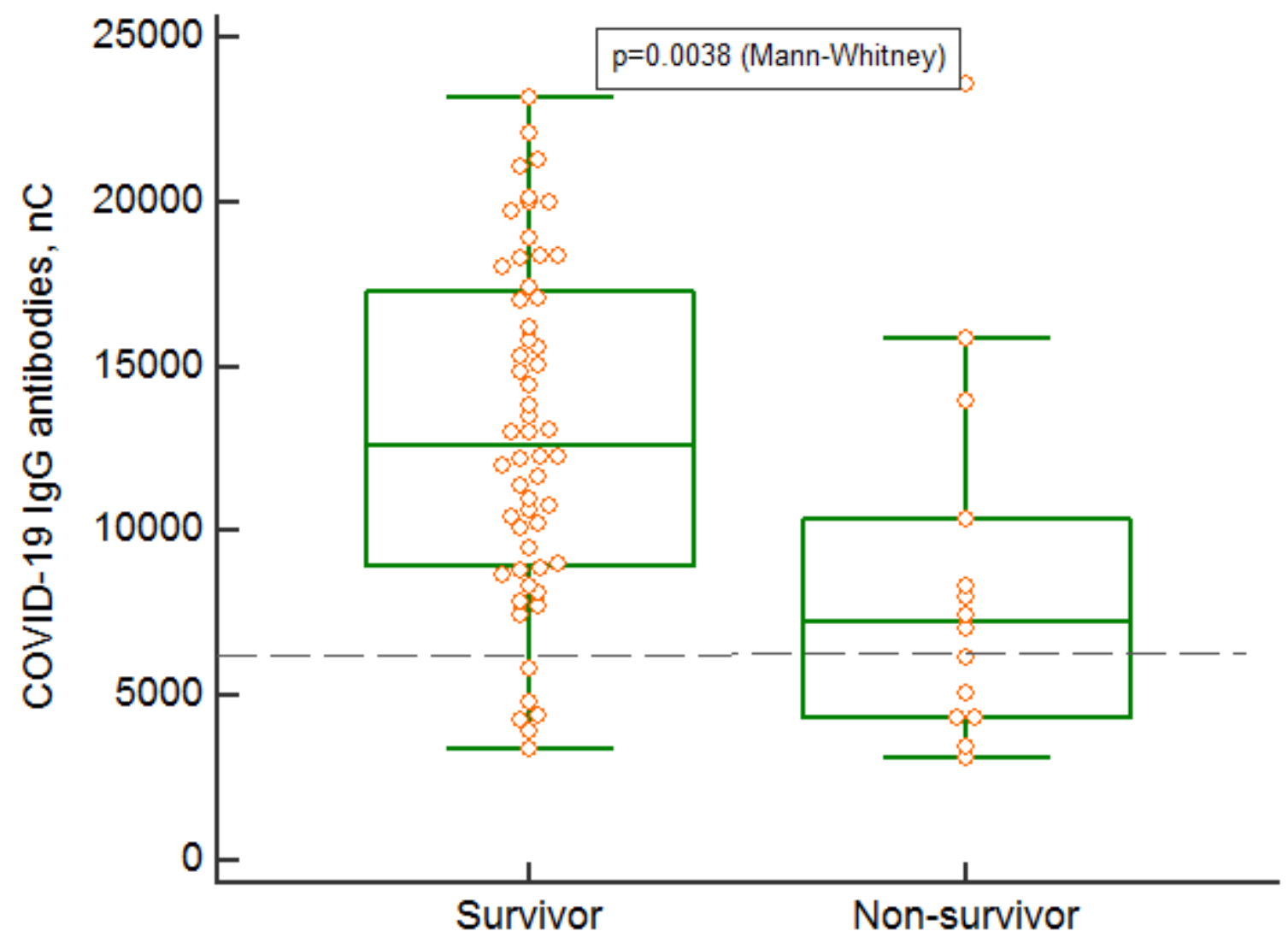

\section{Figure 3}

The IgG antibody response as measured in plasma at admission day at the ICU in relation to survival outcome. The differences between survivors and non-survivors were calculated by Mann-Whitney $U$ test and the statistics given on the figure. 